\title{
Infrared optical properties of spinels
}

\section{A study of the carrier of the 13,17 and $32 \mu \mathrm{m}$ emission features observed in ISO-SWS spectra of oxygen-rich AGB stars*}

\author{
D. Fabian ${ }^{1}$, Th. Posch $^{2}$, H. Mutschke ${ }^{1}$, F. Kerschbaum ${ }^{2}$, and J. Dorschner ${ }^{1}$ \\ 1 Astrophysikalisches Institut und Universitätssternwarte, Schillergässchen 2-3, 07745 Jena, Germany \\ 2 Institut für Astronomie, Türkenschanzstrasse 17, 1180 Wein, Austria \\ Received 16 October 2000 / Accepted 2 May 2001
}

\begin{abstract}
In a previous paper, we have proposed magnesium aluminium spinel to be the carrier of the 13 and $17 \mu \mathrm{m}$ band features observed in the ISO spectra of some red giants. The IR optical properties of spinel strongly depend on its chemistry and its internal structure. To study the dependence of spinel's IR-spectra on its aluminium content, we have synthesized a number of crystals with different $\mathrm{Al} / \mathrm{Mg}$-ratios. Additionally, we performed an annealing experiment to investigate the phase transition between ordered and partially disordered spinel taking place at about $1200 \mathrm{~K}$. We derived sets of optical constants of our natural, annealed and synthetic spinels in order to calculate the absorption efficiencies of small (sub- $\mu$ m-sized) spherical particles. Thereby, it turned out that natural as well as near-stoichiometric synthetic spinel can indeed be considered as a suitable candidate for the carrier of the $13 \mu \mathrm{m}$ feature observed in the spectra of some oxygen rich circumstellar shells. To illustrate this, we reinvestigated the mean profile of the residual dust emission in the $12-18 \mu \mathrm{m}$ wavelength range (i.e., in the so-called trough region between the two silicate bands). The reality of the emission feature at $16.8 \mu \mathrm{m}$ is confirmed by our new investigation. We demonstrated that it is not an instrumental artifact since it is not present in ISO spectra of K-stars. In the course of our laboratory work, we found a third prominent emissivity maximum of spinel at $32 \mu \mathrm{m}$. This feature could also be detected in the spectra of the brightest $13 \mu \mathrm{m}$ band emission sources; we derived its mean band profile, too. The new sets of optical constants here presented have been made available for public access in the electronic database http://www.astro.uni-jena.de.
\end{abstract}

Key words. stars: variables: other - stars: AGB - stars: circumstellar matter - stars: mass-loss - infrared: stars

\section{Introduction}

Since the end of the 1980s, when it was found that IRAS spectra of oxygen rich AGB stars could not be explained in terms of a silicate dust component only, refractory oxides have been considered as candidate substances for features in the mid-IR region, especially in the wavelength range between 10 and $20 \mu \mathrm{m}$. After the discovery of a previously unknown emission band at $12 \mu \mathrm{m}$ by Vardya et al. (1986), Onaka et al. (1989) attributed this feature to $\gamma-\mathrm{Al}_{2} \mathrm{O}_{3}$. Glaccum (1995), analysing spectra taken with the Kuiper Airborne Observatory, found a $13 \mu \mathrm{m}$ feature in some M and MS stars and attributed it to "hot sapphire" (a mineral variety of $\alpha-\mathrm{Al}_{2} \mathrm{O}_{3}$ or corundum).

Begemann et al. (1997), however, have shown that neither $\gamma-\mathrm{Al}_{2} \mathrm{O}_{3}$ nor $\alpha-\mathrm{Al}_{2} \mathrm{O}_{3}$ can account for the $13 \mu \mathrm{m}$

Send offprint requests to: D. Fabian,

e-mail: fabian@astro.uni-jena.de

* Based on observations with ISO, an ESA project with instruments funded by ESA Member States (especially the PI countries: France, Germany, The Netherlands and the UK) and with the participation of ISAS and NASA. emission band, if the simplest assumption concerning the particle shape and size is made. Only in the rather extreme case of ellipsoidal particle shapes, they argued, corundum could account for that feature. As a consequence of this hypothesis, they predicted a second emission feature at $21 \mu \mathrm{m}$, the existence of which could not be verified up to now on the basis of ISO spectra.

A detailed, purely astronomical study of the $13 \mu \mathrm{m}$ feature has been presented by Sloan et al. (1996). They analysed 187 LRS spectra, finding that $75-90 \%$ of all SRb variables, but only $20-25 \%$ of the Miras with oxygen-rich dust show this feature. Hron et al. (1997) found that the $13 \mu \mathrm{m}$ emission peak is observed within a rather narrow range of stellar photospheric and dust shell temperatures, which indicates that the formation of its carrier strongly depends on the physical conditions inside the circumstellar shell.

Kozasa \& Sogawa $(1997,1998)$, studying the dust formation from a theoretical point of view, came to the result that core-mantle-grains composed of $\alpha-\mathrm{Al}_{2} \mathrm{O}_{3}$-cores and silicate mantles play an important role for dust driven 
stellar winds. As a consequence, they expected the presence of a dust emission feature between 13 and $14 \mu \mathrm{m}$ in the spectra of AGB stars with mass loss rates below $2 \times 10^{-5} M_{\odot}$. Posch et al. (1999, henceforth Paper I) could partly verify this hypothesis on the basis of the optical constants of corundum and amorphous $(\mathrm{Mg}$, Fe) $\mathrm{SiO}_{4}$. However, they demonstrated that, if such coremantle particles were responsible for an emission feature in the trough region between the two silicate bands, its position should amount to $14 \mu \mathrm{m}$, showing a tendency to be shifted to even larger wavelengths for smaller core volume fractions (i.e., larger relative strengths of the silicate bands). It was pointed out that neither this band position nor its tendency to increase for larger relative strengths of the silicate bands is consistent with ISO observations.

Furthermore, Paper I contained a discussion of the IRoptical properties of the most important modification of $\mathrm{TiO}_{2}$, rutile, and of $\mathrm{MgAl}_{2} \mathrm{O}_{4}$, spinel. The latter was suggested to be the carrier both of the $13 \mu \mathrm{m}$ and of a newly dicovered $16.8 \mu \mathrm{m}$ emission feature (the reality of which will be confirmed in this paper). Even though the $13 \mu \mathrm{m}$ band is a conspicious emission feature in the spectra of some AGB stars, this does not imply that its carrier is an abundant dust species in the circumstellar shells of the respective stars. As Kerschbaum et al. (2000) have shown, only a few percent $(1-3 \%)$ of the total amount of dust needs to be composed of spinel in order to account for the observed band strengths. This is a consequence of the large maximum intrinsic emissivity of crystalline oxides compared to emissivity of amorphous silicates.

Doubts about the attribution of the $13 \mu \mathrm{m}$ feature to spinel were raised by Speck et al. (2000). They claimed that the dependence of spinel's optical properties on the level of order of its crystal structure was not taken into account by Tropf \& Thomas (1991), on whose optical constants Paper I was based. Instead, they attributed the $13 \mu \mathrm{m}$ emission to silicon dioxide. This disagreement can, on the basis of the ISO spectra and laboratory data now available, be settled rather easily: in this paper, we demonstrate on the one hand that near-stoichiometric spinel dust forming at high temperature has optical properties which are in almost perfect correspondence with three emission features of circumstellar dust (at 13, 17 and $32 \mu \mathrm{m}$ ). On the other hand, we can exclude the existence of a $9.25 \mu \mathrm{m}$ feature, which should be present in the astronomical spectra if silicon oxide were the carrier of the $13 \mu \mathrm{m}$ feature.

An ideal method to find out which kind of dust species do condense in circumstellar envelopes is, in principle, the measurement of molecular depletion rates in stellar photospheres or gaseous outflows. Kerschbaum \& Olofsson (2001) have recently found first indications of an $\mathrm{SiO}$ depletion in the outflows of AGB stars with silicate-rich circumstellar shells. More precisely, they found a decrease in the $\mathrm{SiO} / \mathrm{CO}$ intensity ratio with the pulsational period of Miras, the latter being a very reliable mass-loss indicator. Unfortunately, it is difficult to apply this method to potential precursor molecules of other dust species (like $\mathrm{MgO}$ or $\mathrm{AlO}$ ), since their abundance is by orders of magnitudes smaller.

It is important to note that refractory oxides have also been found as presolar grains in meteorites. Nittler (1997) reported the identification of a large number of corundum grains, as well as one spinel particle and two grains with compositions intermediate between $\mathrm{Al}_{2} \mathrm{O}_{3}$ and spinel, in acid residues of five meteorites. Two grains of a very rare oxide of presolar origin, $\mathrm{CaAl}_{12} \mathrm{O}_{19}$ (hibbonite), were identified in an ordinary chondrite by Choi et al. (1999). Choi et al. (1998) came to the remarkable result that presolar corundum and spinel grains show a large range of $\mathrm{Al} / \mathrm{Mg}$ ratios $(2 \ldots 8)$, interpreting this in terms of a condensation sequence for oxygen-rich circumstellar shells. The starting point of this hypothetical sequence is $\mathrm{Al}_{2} \mathrm{O}_{3}$, which, by cooling and back-reacting with $\mathrm{Mg}$ atoms and water in the gas phase, would be - partially or wholly - transformed to an Mg-Al-oxide (see also Gail 1998).

In view of the lack of optical constants of spinels with different relative $\mathrm{Al}$ and $\mathrm{Mg}$ contents, we synthesized a series of $\mathrm{Mg}$-Al-oxides with spinel structure and derived their optical constants. The result of our work is meant to serve not only for the interpretation of currently available ISO spectra, but also as a data basis for future spectroscopy of circumstellar dust.

This paper is structured as follows. In Sect. 2, we first discuss crystallographic properties of natural and synthetic spinels and describe our method of synthesizing the latter; second, we present reflectance spectra of these samples and try to understand them in terms of lattice vibrations; and third, we calculate the optical constants and absorption efficiencies for small particles. In Sect. 3, we compare the results of our laboratory work with new astronomical observations.

\section{A laboratory investigation of spinels}

\subsection{Internal structure and synthesis of our samples}

The unit cell of natural stoichiometric $\mathrm{Mg}$-Al-spinel consists of 32 oxygen anions, 16 aluminium and 8 magnesium cations. While the trivalent $\mathrm{Al}$ cations occupy a part of the octahedral voids of the cubic close-packed oxygen lattice, the bivalent $\mathrm{Mg}$ ions are situated in tetrahedral interstices. From the examination of synthetic spinels as well as from studies of presolar grains in meteorites mentioned in the introduction, we know that the $\mathrm{Al} / \mathrm{Mg}$-ratio of these crystals is not restricted to the stoichiometric value of 2:1. It occurs that in some or in all of a sample's elementary cells, Mg ions are missing. The tetrahedral sites, therefore, become partly occupied by $\mathrm{Al}$ ions, and vice versa, octahedral sites are partly occupied by $\mathrm{Mg}$ ions, but some of the octahedral sites remain empty. The limiting case with zero $\mathrm{Mg}$ content is the cubic modification of alumina, $\gamma-\mathrm{Al}_{2} \mathrm{O}_{3}$, where $3 / 8$ of the $\mathrm{Al}$ ions are located at tetrahedrally coordinated sites (structural formula $[\mathrm{Al}] \mathrm{Al}_{1.67} \odot_{0.33} \mathrm{O}_{4}$, where [] denotes the tetrahedral sites and $\odot$ the empty octahedral sites). Although 
disordering modifies the local lattice symmetry, the overall cubic crystal symmetry is conserved also for the nonstoichiometric synthetic compounds. We verified by means of X-ray diffraction that the nonstoichiometric compounds do not show significant deviations from the pattern of stoichiometric spinel - except for a linear increase of the lattice constant with increasing $\mathrm{Mg}$ content (see Viertel \& Seifert 1979). Therefore, it is justified to call the former compounds nonstoichiometric spinels (and not just MgAl-oxides). Al-deficient samples can also be synthesized and are designated by the same term.

In view of the astrophysical relevance of nonstoichiometric spinels, we have synthesized a series of them with $\mathrm{Al} / \mathrm{Mg}$-ratios ranging from 4.35 to 1.6. Their designations (Mg10 - Mg05), given in Table 1, correspond to their respective magnesium content. Additionally, we examined an even more Al-rich spinel $(\mathrm{Al} / \mathrm{Mg}=5.53)$ produced by the Verneuil method (see, e.g., Strübel 1995). This sample, henceforth called $\mathrm{Mg} 04$, is colourless, has a diameter of about $1 \mathrm{~cm}$ and a height of $0.5 \mathrm{~cm}$. Furthermore, we investigated a natural spinel before ("Mg10-nat") and after thermal treatment ("Mg10-ann" in Table 1). The sample which we used for our annealing experiment is a dark red, octahedral spinel crystal from Burma with face diameters exceeding $3 \mathrm{~mm}$. Since the diameter of our spectrometer's aperture was $2.5 \mathrm{~mm}$, the crystal's size did not affect the spectra. The crystal's weight, determined after isolating it from the dolomite matrix by means of $\mathrm{HCl}$, is $219 \mathrm{mg}$. Its chemical composition, to an accuracy of $10^{-2}$, is $\mathrm{Mg}_{1.02} \mathrm{Al}_{1.93} \mathrm{Si}_{0.03} \mathrm{Fe}_{0.01} \mathrm{Cr}_{0.01} \mathrm{O}_{4}$. Since the composition has been determined by EDX - a method which is insensitive to light elements -, the oxygen content was added to the formula according to stoichiometry. Although the small $(\leq 3 \%)$ Si, Fe and Cr impurities may affect the spectra from the UV to the NIR range, they are practically irrelevant for the resonance bands in the mid-IR region.

To synthesize our samples Mg10 - Mg05, we chose the following method. $\mathrm{MgCO}_{3}$ and $\mathrm{Al}(\mathrm{OH})_{3}$ powders have been mixed in the corresponding proportions, in order to get a compound mass of $2 \mathrm{~g} \pm 2 \times 10^{-3} \mathrm{~g}$. We did not start with $\mathrm{MgO}$ and $\mathrm{Al}_{2} \mathrm{O}_{3}$, since these oxides are highly refractory. The mixtures have been heated to $1273 \mathrm{~K}$ in corundum crucibles and kept at this temperature for $1 \mathrm{~h}$ to achieve decomposition to the oxides. The products of the decomposition have been homogenized in an agate mortar and were subsequently pressed to pellets. The pellets were transfered to a tungsten electric-arc furnace with a water-cooled copper baseplate where they were molten in a 1 bar argon atmosphere. In the course of this procedure, we obtained melt-droplets which were several millimeters in size and colourless, indicating that contamination with tungsten or copper had not occurred. The samples were exposed to the electric arc until they were fully molten. This means that the formation temperature was 2323 $2408 \mathrm{~K}$ (which are the melting points of corundum and spinel, respectively). According to Andreozzi et al. (2000), in this temperature range, about $37 \%$ of $\mathrm{Mg}$ ions occupy octahedral lattice sites, and the corresponding number of
Al ions moves towards tetrahedral interstices. This partial inversion of the spinel structure occurs rapidly at a high temperature. By contrast, the change from the disordered to the ordered structure occurs only at low temperatures and takes a very long time. Therefore, at least in a shortterm view, the changes can be designated as irreversible. The possibility of re-ordering can not be excluded for long timescales. The structural formula of stoichiometric spinel synthesized at $2400 \mathrm{~K}$ is $\left[\mathrm{Mg}_{0.63} \mathrm{Al}_{0.37}\right] \mathrm{Al}_{1.63} \mathrm{Mg}_{0.37} \mathrm{O}_{4}$ (see Table 1). For Mg-deficient spinels (Mg09 - Mg04), the percentage of $\mathrm{Mg}$ ions at tetrahedral sites remains $37 \%$, but there is not enough magnesium to occupy all of the octahedral sites: an increasing number of voids arise.

After cooling to subliquidous temperature within a few seconds and subsequent cooling to room temperature, selected parts of these samples were subjected to an analysis in a scanning electron microscope equipped with an energy-dispersive X-ray (EDX) analysis tool. The scanning electron microscope (Leo Stereoscan 440i) worked at an accelerating voltage of $20 \mathrm{keV}$ and a beam current of $20 \mathrm{pA}$. The EDX device was calibrated on a cobalt standard. Using this configuration, we measured the elemental composition of the products at five selected spots, $20 \times 20 \mu \mathrm{m}^{2}$ in size. Neither in the stoichiometric spinel nor in the Mg-deficient samples did we find any inhomogeneities. The variation in the $\mathrm{Al} / \mathrm{Mg}$ ratios from spot to spot did not exceed $1 \times 10^{-1}$. The average $\mathrm{Al} / \mathrm{Mg}$ ratios are given in Table 1, Col. 4. The samples showed small deviations from the initial elemental ratios of the powder mixtures. These differences may either be due to selective $\mathrm{MgO}$ evaporation from the melt or due to water adsorption of the powders. We also made use of X-ray diffraction to investigate the crystal structure. Again, it turned out that the samples are crystalline spinels. None of the samples showed any significant inhomogeneities. For the spectroscopic measurements, the samples have been embedded in epoxy resin in order to allow polishing of a plane surface.

\subsection{The reflectance spectra and their meaning}

The reflectance spectra of all samples at near-normal incidence have been measured in an FTIR spectrometer BRUKER $113 \mathrm{v}$ in the wavelength range $2-200 \mu \mathrm{m}$ at a resolution of $2 \mathrm{~cm}^{-1}$. A gold mirror was used for reference. The most interesting parts of the reflectance spectra are shown in Fig. 1. They are characterized by lattice vibrations causing reflection bands in the wavelength region beyond $10 \mu \mathrm{m}$. The spectrum of the sample Mg04, which was synthesized by the Verneuil method, is shown on top of Fig. 1. It fits remarkably well into the series Mg10 $\mathrm{Mg} 05$.

While stoichiometric spinels have been studied extensively both experimentally and within the framework of group theory, the situation is much less favourable for the astrophysically relevant nonstoichiometric spinels. We will approach an understanding of their reflectance spectra in 
Table 1. The sample of synthetic, natural and thermally treated spinels. In the structural formula, the brackets [ ] embrace tetrahedrally coordinated ions; the symbol $\odot$ denotes unoccupied octahedral interstices. The percentage of $\mathrm{Mg}$ ions occupying tetrahedral interstices depends on the formation/annealing temperature. For a formation temperature of about $2400 \mathrm{~K}$, it amounts to 0.37 according to Andreozzi et al. (2000); for an annealing temperature of $1273 \mathrm{~K}$, it amouts to 0.25 . $x_{\mathrm{EDX}}$ is the $\mathrm{Al} / \mathrm{Mg}$-ratio determined by energy-dispersive X-ray analysis performed on selected spots of each sample. Since all values are rounded out to two decimals, a full compatibility of the $x$ values and the respective values in the sum formulae could not be achieved. The asterisks in the last two lines indicate that the impurities in the natural spinel crystal have not been taken into account in the respective formulae.

\begin{tabular}{|c|c|c|c|c|}
\hline Designation & sum formula & structural formula & $x_{\mathrm{EDX}}$ & Maxima of $R(\lambda)[\mu \mathrm{m}]$ \\
\hline Mg10 & $\mathrm{Mg}_{1.01} \mathrm{Al}_{1.99} \mathrm{O}_{4}$ & {$\left[\mathrm{Mg}_{0.64} \mathrm{Al}_{0.36}\right] \mathrm{Al}_{1.63} \mathrm{Mg}_{0.37} \mathrm{O}_{4}$} & 1.96 & $13.6,18.4,33.0$ \\
\hline Mg09 & $\mathrm{Mg}_{0.94} \mathrm{Al}_{2.04} \mathrm{O}_{4}$ & {$\left[\mathrm{Mg}_{0.59} \mathrm{Al}_{0.41}\right] \mathrm{Al}_{1.63} \mathrm{Mg}_{0.35} \odot_{0.02} \mathrm{O}_{4}$} & 2.19 & $13.8,18.3,33.0$ \\
\hline Mg08 & $\mathrm{Mg}_{0.82} \mathrm{Al}_{2.12} \mathrm{O}_{4}$ & {$\left[\mathrm{Mg}_{0.52} \mathrm{Al}_{0.48}\right] \mathrm{Al}_{1.64} \mathrm{Mg}_{0.30} \odot_{0.06} \mathrm{O}_{4}$} & 2.59 & $12.2,13.8,18.3,33.1$ \\
\hline $\mathrm{Mg} 07$ & $\mathrm{Mg}_{0.73} \mathrm{Al}_{2.17} \mathrm{O}_{4}$ & {$\left[\mathrm{Mg}_{0.46} \mathrm{Al}_{0.54}\right] \mathrm{Al}_{1.63} \mathrm{Mg}_{0.27} \odot_{0.10} \mathrm{O}_{4}$} & 3.03 & $12.1,13.8,18.3,33.1$ \\
\hline $\mathrm{Mg} 05$ & $\mathrm{Mg}_{0.53} \mathrm{Al}_{2.31} \mathrm{O}_{4}$ & {$\left[\mathrm{Mg}_{0.33} \mathrm{Al}_{0.67}\right] \mathrm{Al}_{1.64} \mathrm{Mg}_{0.20} \odot_{0.16} \mathrm{O}_{4}$} & 4.35 & $12.0,14.0,18.2,33.1$ \\
\hline $\mathrm{Mg04}$ & $\mathrm{Mg}_{0.43} \mathrm{Al}_{2.38} \mathrm{O}_{4}$ & {$\left[\mathrm{Mg}_{0.27} \mathrm{Al}_{0.73}\right] \mathrm{Al}_{1.65} \mathrm{Mg}_{0.16} \odot_{0.19} \mathrm{O}_{4}$} & 5.53 & $11.9,14.1,18.3,32.9$ \\
\hline Mg10-nat* & $\mathrm{Mg}_{1.02} \mathrm{Al}_{1.93} \mathrm{O}_{4}$ & {$\left[\mathrm{Mg}_{1.02}\right] \mathrm{Al}_{1.93} \mathrm{O}_{4}$} & 1.89 & $13.8,17.0,18.6,32.6$ \\
\hline Mg10-ann* & $\mathrm{Mg}_{1.02} \mathrm{Al}_{1.93} \mathrm{O}_{4}$ & {$\left[\mathrm{Mg}_{0.76} \mathrm{Al}_{0.24}\right] \mathrm{Al}_{1.69} \mathrm{Mg}_{0.26} \mathrm{O}_{4}$} & 1.89 & $13.6,18.6,33.2$ \\
\hline
\end{tabular}

two steps: first by summarizing the current knowledge about the "ideal" natural, stoichiometric $\mathrm{MgAl}_{2} \mathrm{O}_{4}$, and second by outlining in which way synthetic spinels differ from it. The latter point will involve a description of an annealing experiment carried out with a natural spinel, since it has turned out that annealed natural spinel shows noteworthy structural similarity with synthetic spinels.

From group theory, four IR active modes were predicted for $\mathrm{MgAl}_{2} \mathrm{O}_{4}$ (see White \& De Angelis 1967; O'Horo et al. 1973). The two most prominent of them correspond to maxima of the reflectivity around 14 and $18 \mu \mathrm{m}$. For the sake of brevity, we denominate the $14 \mu \mathrm{m}$ mode "A", whereas we call the $18 \mu \mathrm{m}$ mode "B" (see Fig. 1). In powder transmission measurements, the modes A and B cause minima of $T(\lambda)$ situated at about 15 and $19 \mu \mathrm{m}$; in small particle spectra, they correspond to maxima of the absorption efficiency $C_{\mathrm{abs}}(\lambda)$ around 13 and $17 \mu \mathrm{m}$ (see Sect. 2.3). Comparing these band positions with spectra of $\alpha-\mathrm{Al}_{2} \mathrm{O}_{3}$ and of $\mathrm{MgO}$, one might be tempted to assume that mode $\mathrm{A}$ is due to an $\mathrm{Al}-\mathrm{O}$ vibration, while mode $\mathrm{B}$ would originate from an $\mathrm{Mg}-\mathrm{O}$ vibration. But this is not the case, as Preudhomme \& Tarte (1971) have shown in a careful investigation. They demonstrated that both of the above mentioned resonances mainly originate from vibrations of the trivalent, octahedral cation in the spinel lattice, i.e. from an $\mathrm{Al}-\mathrm{O}$ vibration in the case of $\mathrm{Mg}-\mathrm{Al}$-spinels. In other words, both the frequency of mode $\mathrm{A}$ and mode $\mathrm{B}$ is practically independent of the bivalent, tetrahedral cation. If, for example, the $\mathrm{Mg}$ ions in $\mathrm{MgAl}_{2} \mathrm{O}_{4}$ are completely replaced by $\mathrm{Co}$ ions, the modes $\mathrm{A}$ and $\mathrm{B}$ do not change their frequencies significantly.

The remaining two theoretically predicted IR active modes of $\mathrm{MgAl}_{2} \mathrm{O}_{4}$ are positioned as follows: one, which we shall call "C" in Fig. 3, at the short-wavelength edge of mode B; and one, called "D", far beyond mode B, at $33 \mu \mathrm{m}$. According to Preudhomme \& Tarte (1971), mode $\mathrm{D}$ must be assigned to an $\mathrm{Mg}-\mathrm{O}$ vibration, whereas mode $\mathrm{C}$ is of a more complex origin.
Reconsidering Fig. 1 with this background, we notice that no maximum of $R(\lambda)$ shows up between 14 and $18 \mu \mathrm{m}$ : mode $\mathrm{C}$ is, for a reason which will be specified later in this section, not visible in any of our spectra. Mode D shows a tendency to become weaker with decreasing $\mathrm{Mg}$ content. (This is in good agreement with Preudhomme \& Tarte's 1971, assignment of this mode to an Mg-O vibration.) On the other hand, in the spectra of the Al-rich samples (Mg08 - Mg04), two additional resonance modes become visible at about 12 and $11 \mu \mathrm{m}$. For the most Al-rich spinel of our sample, the reflectance maximum at $12 \mu \mathrm{m}$ becomes as prominent as the one at $14 \mu \mathrm{m}$.

In Fig. 2, we compare the reflectance of a selected Alrich spinel with the reflectance of $\gamma-\mathrm{Al}_{2} \mathrm{O}_{3}$, which, due to its cubic crystal structure, can be considered as an Mg-free defect spinel. This comparison makes it probable that the $12 \mu \mathrm{m}$ reflectance maximum observed in the spectra of nonstoichiometric synthetic spinels is in some way related to the principal peak in the reflectance spectrum of $\gamma-\mathrm{Al}_{2} \mathrm{O}_{3}$. It seems that the $12 \mu \mathrm{m}$ resonance mode corresponds to an Al-O vibration involving tetrahedrally coordinated Al-ions (whereas the group theoretical calculations mentioned are based on the assumption that all of the Al-ions are octrahedrally coordinated, which is indeed the case for stoichiometric spinels). Alluding to the relation between the $12 \mu \mathrm{m}$ peak both in the spectra of Al-rich spinels and of $\gamma-\mathrm{Al}_{2} \mathrm{O}_{3}$, we have called the corresponding resonance mode "G" (reminding us of gamma) in Fig. 1.

The fact that Al-rich spinels exhibit an additional resonance mode at an even higher frequency than mode A was already pointed out by Hafner \& Laves (1961). However, these authors focused on powder transmission measurements, whereas in the context of astrophysics, optical constants and absorption cross sections are desirable (see Sect. 2.3).

Independently from Hafner's \& Laves' work, Chihara et al. (2000) also report the observation of an additional reflectance maximum of an Al-rich synthetic spinel at a wavelength of $11.9 \mu \mathrm{m}$. Of course, this reflectance 


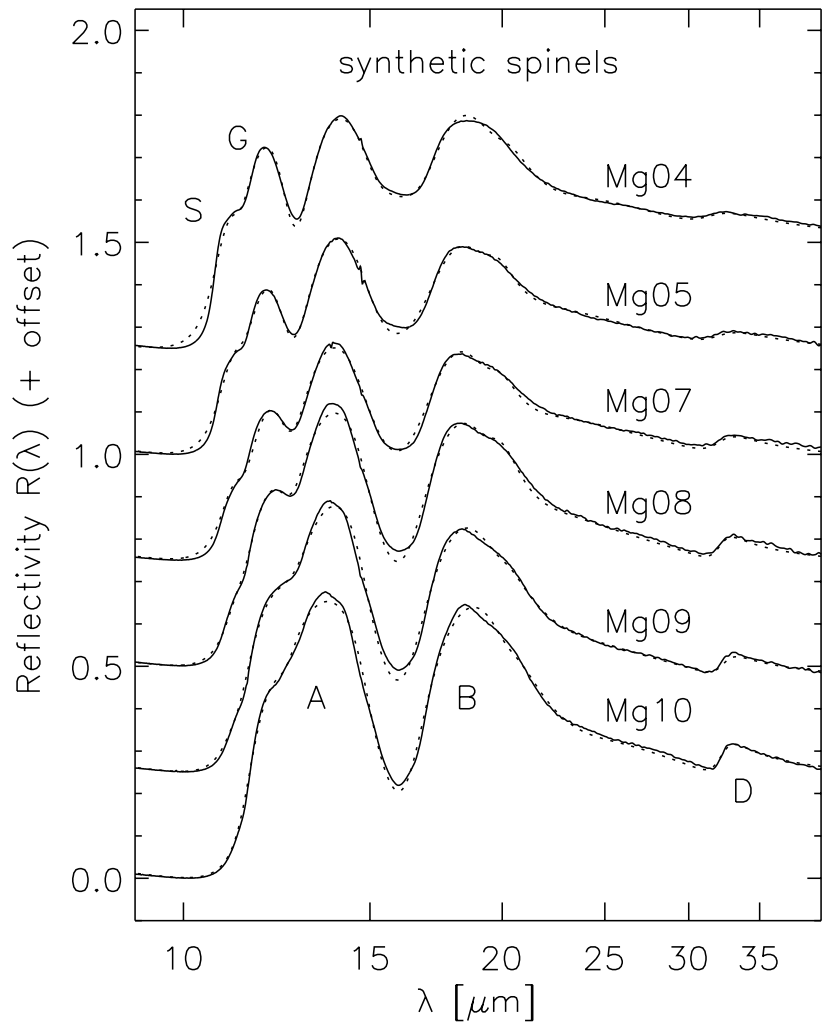

Fig. 1. The reflectance spectra of synthetic spinels with relative $\mathrm{Mg}$ contents amounting to 1.01, 0.94, 0.82, 0.73, 0.53 and 0.43 (solid lines, from the bottom to the top). For the sake of clearness, the reflectances were successively shifted along the $y$-axis by an amount of 0.25 . In the spectra of the samples with a relative $\mathrm{Mg}$ content $<0.9(\mathrm{Mg} 08-\mathrm{Mg} 04)$, the shoulder at the "blue" wing of the $14 \mu \mathrm{m}$ peak (A) is enhanced to an additional band $(\mathrm{G})$, accompanied by the development of a fourth shoulder (S) at its "blue" side (for the meaning of the letters A, B, D, G and S see also text). The dotted lines represent the Lorentzian fits of the spectra which we used to derive the optical constants.

maximum corresponds to the mode that we call G. There is another respect in which the results of Chihara et al. (2000) are remarkable: for their Al-rich spinel, they additionally find a resonance at $11.2 \mu \mathrm{m}$. On the basis of our sample, we came to the same result. Due to the fact that we systematically synthesized spinels with a wide range of $\mathrm{Al} / \mathrm{Mg}$-ratios, we recognized that the $11.2 \mu \mathrm{m}$ resonance - which appears as a shoulder $(S)$ of the G band - becomes stronger when the $\mathrm{Al} / \mathrm{Mg}$-ratio increases and more Al-ions occupy tetrahedral interstices of the anion lattice (see again Fig. 1).

We shall now address the question why we do not, in any of the spectra shown in Fig. 1, see any trace of the mode $\mathrm{C}$, which is supposed to produce a maximum of $R(\lambda)$ near $17 \mu \mathrm{m}$. This problem will turn out to be identical with the question of how synthetic spinels, even if stoichiometric like our $\mathrm{Mg} 10$, differ from natural ones in their spectra and in their internal structure.

Having learned from Hafner \& Laves (1961) that both synthetic and annealed natural spinels are characterized

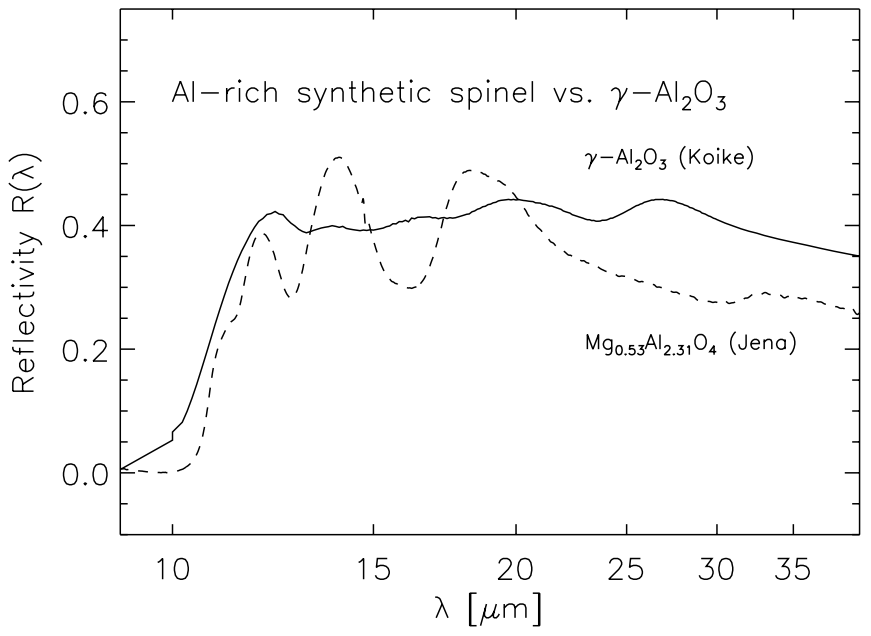

Fig. 2. Comparison between the measured reflectivity of a highly Al-rich synthetic spinel and the reflectivity of $\gamma-\mathrm{Al}_{2} \mathrm{O}_{3}$. The latter has been calculated from the data published by Koike et al. (1995). Note that these data may be affected by particle shape effects, since they have been derived from powder transmission measurements.

by a disordered cation distribution, we carried out an annealing experiment with the natural spinel from Burma described in Sect. 2.1. After measuring the spectrum of the unannealed crystal with our Bruker 113v FTIR spectrometer, we annealed the sample for $1 \mathrm{~h}$ at $1223 \mathrm{~K}$, let it cool down to room temperature and repeated the spectroscopic measurement. The result of this experiment is shown in Fig. 3.

It can be clearly seen that

a) resonance mode $\mathrm{A}$ is slightly sharper before the annealing than afterwards (to verify this, look at the minimum of $R(\lambda)$ at about $16 \mu \mathrm{m})$;

b) mode $\mathrm{C}$ is only visible as a weak shoulder of mode $\mathrm{B}$ in the spectra of annealed and synthetic spinels;

c) mode D has also become weaker after annealing, and it is weak, too, in synthetic spinels.

The reason for these effects is an irreversible structural change occuring when spinel is exposed to temperatures above 1200 K. Natural spinel crystals which have not been heated show a well ordered distribution of the $\mathrm{Mg}$ and $\mathrm{Al}$ cations among the tetrahedrally and octahedrally coordinated voids of the anion lattice, as it was described at the beginning of the Sect. 2.1. Both annealed and synthetic crystals, by contrast, have a disordered cation distribution. This heat-induced disorder involves a partial transition of $\mathrm{Al}$ ions to tetrahedral sites and of $\mathrm{Mg}$ ions to octahedral sites.

The maximum reflectance values which have recently been presented by Chihara et al. (2000) are systematically higher (by about 10\%) than ours. In view of this discrepancy, we checked the absolute accuracy of our reflection measurements by means of a polished bulk silicon standard. However, this did not change our results.

If spinel does indeed condense in circumstellar envelopes, one would expect it to be characterized rather by 

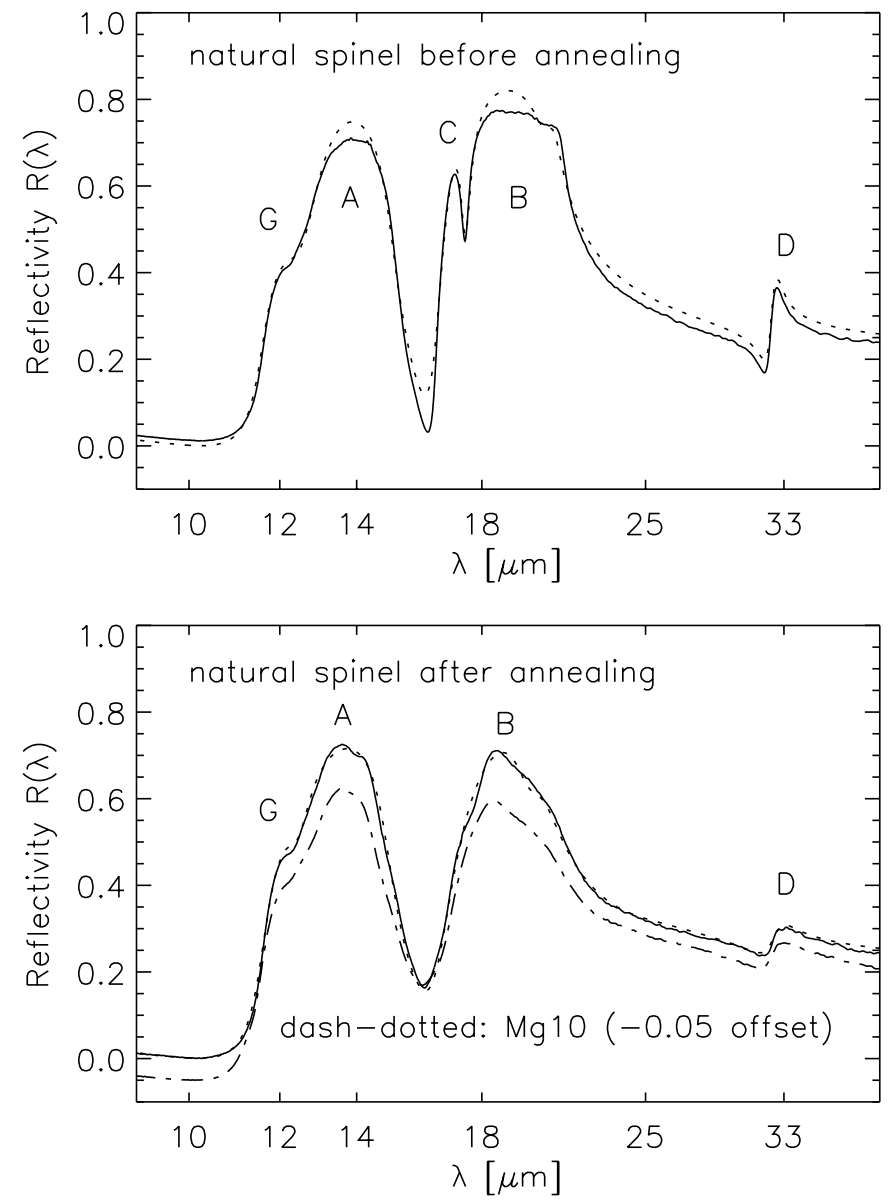

Fig. 3. The IR reflectivity of a near-stoichiometric natural spinel before and after annealing. Note the presence of a reflectance maximum labeled "C" at $17 \mu \mathrm{m}$ in the spectrum of the unannealed sample, which has almost disappeared after the annealing and which is also missing in the spectra of synthetic spinels (the dash-dotted line, refering to the sample $\mathrm{Mg} 10$, illustrates this). The dotted line refers to the oscillator fits which have been used for deriving the optical constants.

the disordered lattice structure of annealed (or synthetic) spinel than by that of the natural mineral. On the one hand, this becomes clear from the consideration of condensation as a non-equilibrium process. On the other hand, it is a plausible consequence of spinel's high formation temperature (about $1300 \mathrm{~K}$, according to Sedlmayr \& Krüger 1997, Fig. 8) and of the short-term irreversibility of the strucural change discussed above. And indeed, we shall see in Sect. 3 that small particle spectra of annealed natural spinel are in good agreement with the dust emission profile derived from ISO spectra.

In Paper I, we used the optical constants published by Tropf \& Thomas (1991), which have recently been critizised by Speck et al. (2000) as "moot" because of the former authors' failure to discuss the effects of nonstoichiometry and of disordered lattice structure. Having extensively studied the impact of these effects on spinel's IR reflectance spectra, we are now in the position

(i) to present reliable optical constants of spinels for a wide range of $\mathrm{Al} / \mathrm{Mg}$-ratios as well as for different degrees of ordering, and to derive small-particle spectra from them; (ii) to state that Tropf \& Thomas' data represent an acceptable data set for stoichiometric synthetic spinels; this data set turns out to be a special case of our much larger one, but is not criticable as such.

\subsection{Optical constants and small particle spectra}

To derive the optical constants $n(\lambda)$ and $k(\lambda)$ from the reflectance spectra, we relied on the classical Lorentz oscillator model, according to which the dielectric function $\epsilon(\nu)$ is given by:

$\epsilon(\nu)=\epsilon_{\infty}+\sum_{j} \frac{\Omega_{j}^{2}}{\mathrm{TO}_{j}^{2}-\nu^{2}-i \gamma_{j} \nu}$

where $\Omega_{j}^{2}$ is the respective oscillator strength, $\gamma_{j}$ the damping constant, and $\mathrm{TO}_{j}$ the resonance frequency of the $j$ th oscillator. We adopted the oscillator parameters of stoichiometric spinel due to Tropf \& Thomas (1991) as start values for a fitting procedure. Additionally, we took into account an oscillator which accounts for the high energy vibrational mode "S" shown in Fig. 1. By means of a dielectric function modelling code, we iteratively varied the vibrational frequencies, oscillator strengths and damping constants, until the best possible overall agreement with the laboratory spectra was achieved (see Figs. 1 and 3). In Table 2, the oscillator fit parameters are given explicitly.

The optical constants which we finally derived - Fig. 4 shows some examples of them - are consistent with the respective measured reflectivities. Additionally performed Kramers-Kronig analysis yielded no significant improvement of our results. Tables of $n(\lambda)$ and $k(\lambda)$ for all of the nonstoichiometric spinels listed in Table 1 as well as the Lorentz fit parameters can be retrieved from the Jena laboratory homepage (see Henning et al. 1999).

Figure 4 is a good illustration of our claim that it makes a large difference whether one uses the optical constants of unannealed natural or those of synthetic spinel. Despite the nearly identical chemistry of the natural sample and the sample "Mg10", their $n(\lambda)$ and $k(\lambda)$ are quite different from each other. This is a consequence of the heat-induced disorder both in the lattice of synthetic and of annealed spinels.

From the optical constants, the volume normalized scattering and absorption cross sections of small spherical dust particles can be calculated. The latter quantity, $C_{\text {abs }} / V$, is also called emissivity, since for optically thin dust shells, it governs the dust emission profile. Recall that in the Rayleigh-limit (i.e. for particles small compared to the wavelength), the emissivity of spheres can be derived from the complex refractive index $m=n+\mathrm{i} k$ by the simple relation:

$\frac{C_{\mathrm{abs}}}{V}=\frac{6 \pi}{\lambda} \Im\left(\frac{m^{2}-1}{m^{2}+2}\right)$

(see, e.g., Bohren \& Huffman 1983). 
Table 2. Frequencies $\left(\mathrm{TO}_{j}\right)$, oscillator strengths $\left(\Omega_{j}\right)$ and damping constants $\left(\gamma_{j}\right)$ for the oscillator fits of our reflection spectra of synthetic spinels using Eq. (1). The dielectric constant was set for all samples according to $\epsilon_{\infty}=2.892$. The designations of the modes essentially correspond to those of the reflectance bands. Note that the reflectance band $B$ corresponds to a combination of two oscillators, $B_{1}$ and $B_{2}$. Two harmonic oscillator modes with very large damping constants remain without designation.

\begin{tabular}{|c|c|c|c|c|}
\hline Sample & Mode & $\begin{array}{l}\mathrm{TO}_{j} \\
\left(\mathrm{~cm}^{-1}\right)\end{array}$ & $\begin{array}{l}\Omega_{j} \\
\left(\mathrm{~cm}^{-1}\right)\end{array}$ & $\begin{array}{l}\gamma_{j} \\
\left(\mathrm{~cm}^{-1}\right)\end{array}$ \\
\hline \multirow[t]{8}{*}{ Mg10 } & \multirow[t]{2}{*}{$\mathrm{D}$} & 307.5 & 163.6 & 21.8 \\
\hline & & 403.0 & 300.5 & 100.8 \\
\hline & $\mathrm{B}_{2}$ & 481.1 & 514.4 & 46.2 \\
\hline & \multirow[t]{2}{*}{$\mathrm{B}_{1}$} & 505.5 & 694.7 & 51.2 \\
\hline & & 581.4 & 254.4 & 166.4 \\
\hline & A & 673.9 & 564.7 & 49.1 \\
\hline & G & 805.3 & 94.3 & 58.7 \\
\hline & S & 876.0 & 2.1 & 47.3 \\
\hline \multirow[t]{8}{*}{ Mg09 } & \multirow[t]{2}{*}{$\mathrm{D}$} & 307.3 & 123.0 & 22.5 \\
\hline & & 414.9 & 179.6 & 79.2 \\
\hline & $\mathrm{B}_{2}$ & 492.3 & 383.7 & 39.8 \\
\hline & \multirow[t]{2}{*}{$\mathrm{B}_{1}$} & 517.2 & 764.4 & 61.7 \\
\hline & & 606.3 & 286.8 & 174.6 \\
\hline & A & 676.7 & 575.2 & 46.2 \\
\hline & $\mathrm{G}$ & 794.2 & 191.6 & 96.9 \\
\hline & S & 897.2 & 49.6 & 50.6 \\
\hline \multirow[t]{8}{*}{ Mg08 } & \multirow[t]{2}{*}{$\mathrm{D}$} & 309.1 & 140.5 & 21.0 \\
\hline & & 445.7 & 510.6 & 126.7 \\
\hline & $\mathrm{B}_{2}$ & 497.0 & 527.6 & 39.4 \\
\hline & \multirow[t]{2}{*}{$\mathrm{B}_{1}$} & 525.0 & 574.4 & 61.2 \\
\hline & & 620.0 & 274.8 & 173.6 \\
\hline & A & 673.1 & 555.2 & 55.2 \\
\hline & G & 798.9 & 179.8 & 67.0 \\
\hline & $\mathrm{S}$ & 885.0 & 61.9 & 52.9 \\
\hline \multirow[t]{8}{*}{ Mg07 } & \multirow[t]{2}{*}{$\mathrm{D}$} & 309.1 & 141.1 & 29.7 \\
\hline & & 445.7 & 600.0 & 150.0 \\
\hline & $\mathrm{B}_{2}$ & 500.0 & 370.9 & 41.7 \\
\hline & \multirow[t]{2}{*}{$\mathrm{B}_{1}$} & 532.0 & 560.0 & 64.9 \\
\hline & & 617.1 & 289.5 & 160.4 \\
\hline & A & 679.1 & 566.5 & 72.3 \\
\hline & $\mathrm{G}$ & 804.0 & 227.5 & 62.0 \\
\hline & S & 885.1 & 110.7 & 55.1 \\
\hline \multirow[t]{8}{*}{$\mathrm{Mg} 05$} & \multirow[t]{2}{*}{$\bar{D}$} & 309.7 & 142.7 & 39.0 \\
\hline & & 450.0 & 605.0 & 151.9 \\
\hline & $\mathrm{B}_{2}$ & 501.4 & 391.4 & 40.6 \\
\hline & \multirow[t]{2}{*}{$\mathrm{B}_{1}$} & 531.4 & 564.7 & 69.5 \\
\hline & & 622.0 & 339.9 & 135.7 \\
\hline & A & 676.0 & 540.1 & 68.9 \\
\hline & G & 804.7 & 271.6 & 58.4 \\
\hline & $\mathrm{S}$ & 882.6 & 107.9 & 57.1 \\
\hline \multirow[t]{8}{*}{$\mathrm{Mg} 04$} & \multirow[t]{2}{*}{$\bar{D}$} & 314.9 & 172.9 & 44.0 \\
\hline & & 422.6 & 563.4 & 139.6 \\
\hline & $\mathrm{B}_{2}$ & 490.3 & 475.4 & 51.2 \\
\hline & \multirow[t]{2}{*}{$\mathrm{B}_{1}$} & 522.4 & 648.3 & 66.9 \\
\hline & & 628.0 & 434.2 & 104.8 \\
\hline & A & 672.7 & 463.8 & 67.8 \\
\hline & $\mathrm{G}$ & 800.9 & 287.8 & 52.2 \\
\hline & $\mathrm{S}$ & 888.4 & 99.8 & 49.8 \\
\hline
\end{tabular}

Table 2. continued.

\begin{tabular}{l|l|l|l|l}
\hline Sample & Mode & $\begin{array}{l}\mathrm{TO}_{j} \\
\left(\mathrm{~cm}^{-1}\right)\end{array}$ & $\begin{array}{l}\Omega_{j} \\
\left(\mathrm{~cm}^{-1}\right)\end{array}$ & $\begin{array}{l}\gamma_{j} \\
\left(\mathrm{~cm}^{-1}\right)\end{array}$ \\
\hline Mg10-nat & $\mathrm{D}$ & 308.1 & 151.0 & 6.9 \\
& $\mathrm{~B}_{2}$ & 478.6 & 655.5 & 14.0 \\
& $\mathrm{~B}_{1}$ & 492.4 & 660.2 & 30.8 \\
& $\mathrm{C}$ & 577.3 & 132.1 & 11.5 \\
& $\mathrm{~A}$ & 666.6 & 522.9 & 31.9 \\
& $\mathrm{G}$ & 803.6 & 159.7 & 82.5 \\
\hline Mg10-ann & $\mathrm{D}$ & 306.9 & 142.0 & 17.0 \\
& & 404.7 & 267.3 & 102.9 \\
& $\mathrm{~B}_{2}$ & 488.5 & 707.6 & 35.6 \\
& $\mathrm{~B}_{1}$ & 511.3 & 471.7 & 32.5 \\
& $\mathrm{C}$ & 575.7 & 261.5 & 163.7 \\
& $\mathrm{~A}$ & 672.6 & 564.0 & 35.9 \\
& $\mathrm{G}$ & 806.8 & 90.1 & 49.1 \\
& $\mathrm{~S}$ & 872.4 & 2.1 & 49.2 \\
\hline
\end{tabular}
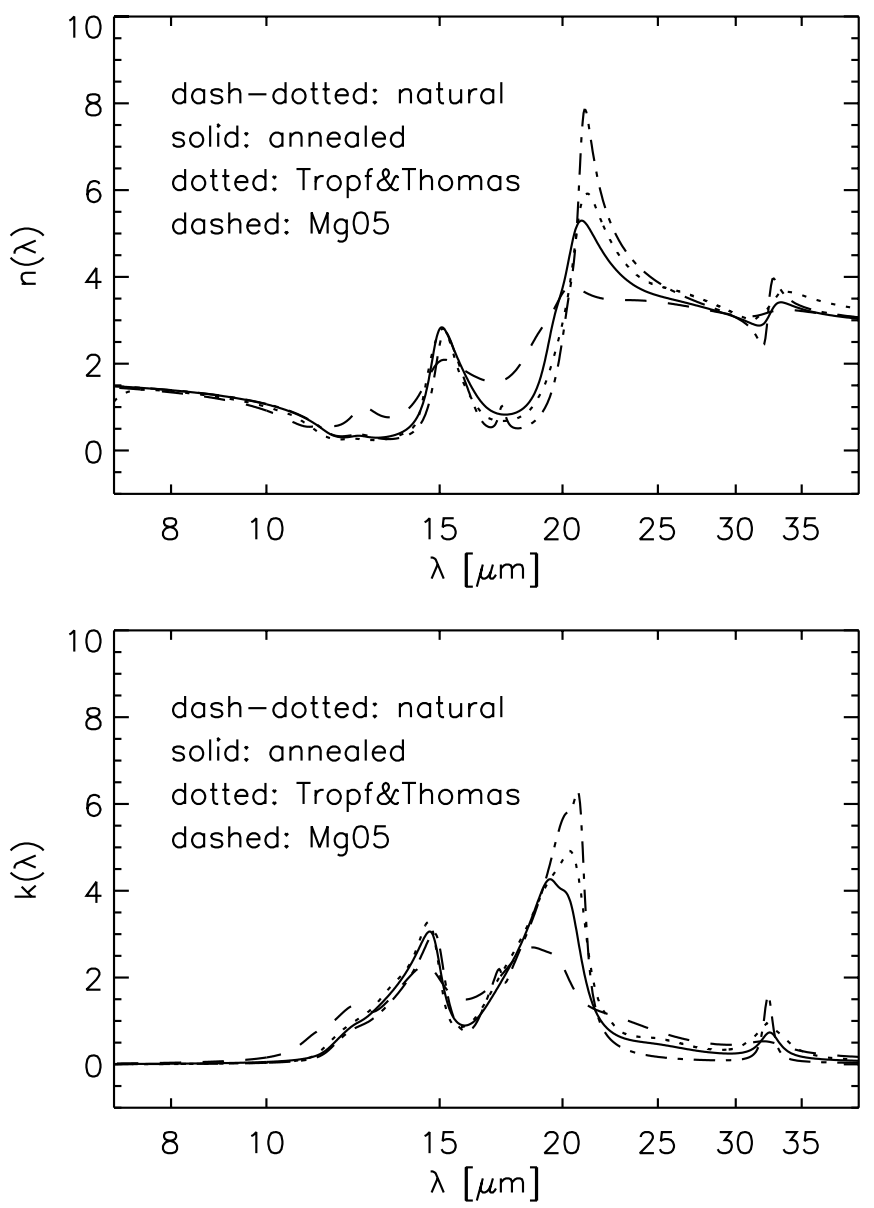

Fig. 4. The optical constants of four selected spinels, plotted on a log-linear scale. Note the large difference between the optical constants of unannealed natural and annealed spinel.

Assuming the circumstellar spinel particles to be sub$\mu \mathrm{m}$-sized and (nearly) spherical, their emissivity profile can with sufficient precision be calculated with this equation. The result is shown in Figs. 5, 6 and - as far as the band positions are concerned - in Table 3. There is 

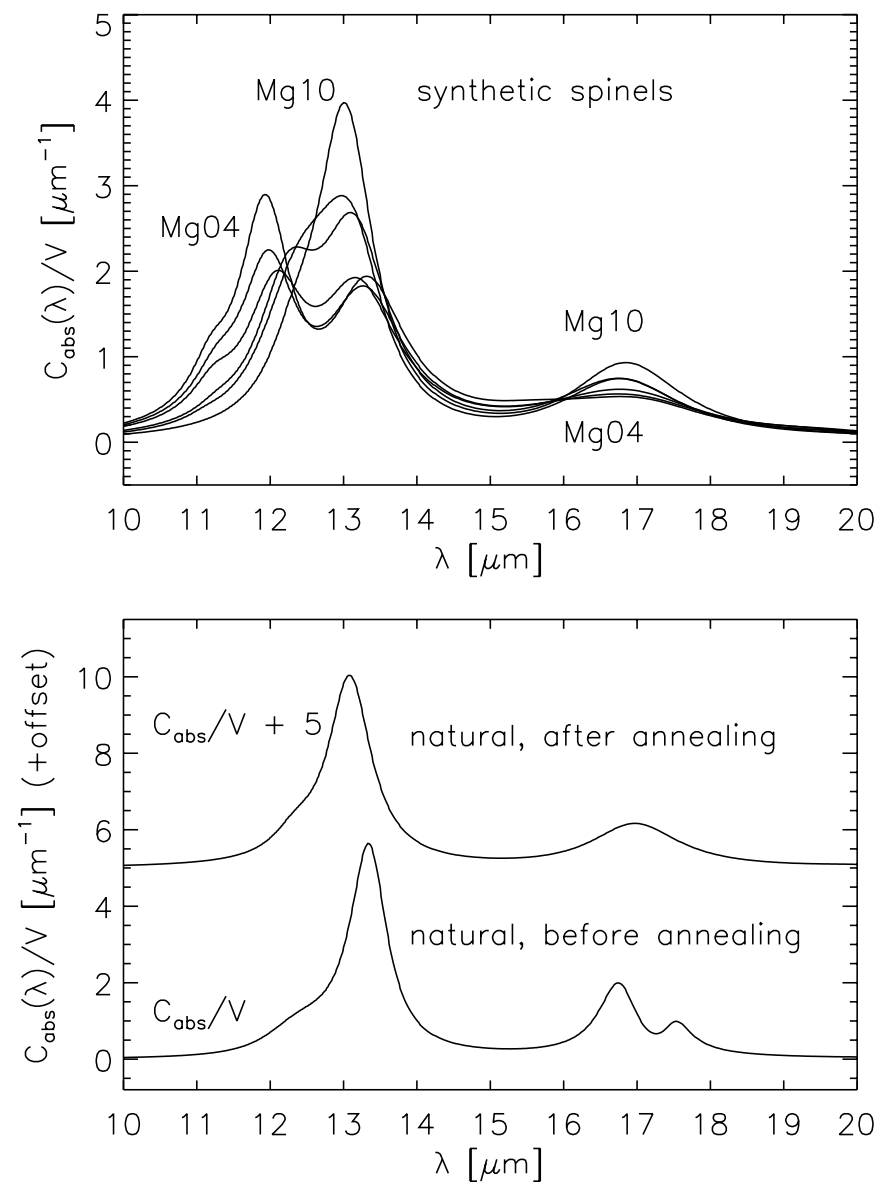

Fig. 5. Upper panel: the mid-IR emissivity of the synthetic spinels Mg04, Mg05, Mg07, Mg08, Mg09 and Mg10 in the wavelength range from $10-20 \mu \mathrm{m}$, plotted on a linear scale. Lower panel: same as above, but for a natural spinel before and after the annealing experiment described in Sect. 2.2. Note the loss of fine structure in the $17 \mu \mathrm{m}$ emissivity peak after annealing.

one respect in which the spectra shown in these figures differ from all of the previous ones: due to the factor $6 \pi / \lambda$ occuring at the right-hand-side of Eq. (2), the values of $C_{\text {abs }}$ strongly decrease towards longer wavelengths (which is not the case for the reflectance, nor for the optical constants). Therefore, spinel's resonance mode "B" produces a weaker peak than resonance mode "A" - even though the intrinsic oscillator strength of mode B is larger than that of mode A. On the other hand, the high-energy (short wavelength) resonance mode "G" - which we have seen to be characteristic of Al-rich spinels - is very prominent in the small particle spectra. For Mg04, Mg05 and $\mathrm{Mg} 07$, the $12 \mu \mathrm{m} C_{\text {abs-peak corresponding to this mode is }}$ as high as the $13 \mu \mathrm{m}$ peak, or even higher. For the stoichiometric sample Mg10, the $13 \mu \mathrm{m}$ emissivity maximum is the clearly dominant spectral feature, whereas a secondary peak at $17 \mu \mathrm{m}$ (corresponding, of course, to the vibrational mode B) is less prominent by a factor of four. As we shall see in Sect. 3.1, the emissivity of a stoichiometric (or near-stoichiometric) spinel is rather well consistent with the emissivity of the carrier of the astronomical $13 \mu \mathrm{m}$ feature.

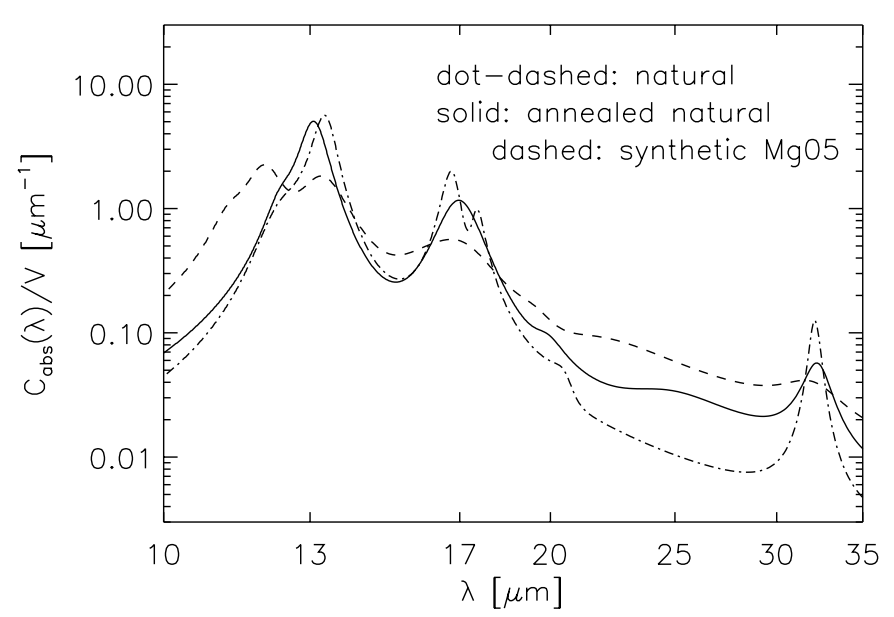

Fig. 6. The IR emissivity of an unannealed natural, an annealed and an Al-rich synthetic spinel (Mg05), shown on a $\log -\log$ scale. Note the peak around $32 \mu \mathrm{m}$, which originates from an $\mathrm{Mg}-\mathrm{O}$ vibration (resonance mode "D").

Table 3. Overview of the positions of the maxima of $C_{\text {abs }} / V$ for small spherical spinel particles with different $\mathrm{Al} / \mathrm{Mg}$-ratios.

\begin{tabular}{lcc}
\hline Designation & sum formula & Maxima of $C_{\text {abs }}(\lambda)[\mu \mathrm{m}]$ \\
\hline Mg10-nat & $\mathrm{Mg}_{1.02} \mathrm{Al}_{1.93} \mathrm{O}_{4}$ & $13.3,16.8,17.5,32.2$ \\
Mg10-ann & $\mathrm{Mg}_{1.02} \mathrm{Al}_{1.93} \mathrm{O}_{4}$ & $13.1,17.0,32.3$ \\
\hline $\mathrm{Mg} 10$ & $\mathrm{Mg}_{1.01} \mathrm{Al}_{1.99} \mathrm{O}_{4}$ & $13.0,16.9,32.0$ \\
Mg09 & $\mathrm{Mg}_{0.94} \mathrm{Al}_{2.04} \mathrm{O}_{4}$ & $13.0,16.8,32.3$ \\
$\mathrm{Mg} 08$ & $\mathrm{Mg}_{0.82} \mathrm{Al}_{2.12} \mathrm{O}_{4}$ & $13.1,16.8,32.0$ \\
$\mathrm{Mg} 07$ & $\mathrm{Mg}_{0.73} \mathrm{Al}_{2.17} \mathrm{O}_{4}$ & $12.1,13.2,16.8,31.8$ \\
$\mathrm{Mg} 05$ & $\mathrm{Mg}_{0.53} \mathrm{Al}_{2.31} \mathrm{O}_{4}$ & $12.0,13.3,16.8,31.6$ \\
$\mathrm{Mg} 04$ & $\mathrm{Mg}_{0.43} \mathrm{Al}_{2.38} \mathrm{O}_{4}$ & $11.9,13.3,16.8,30.7$ \\
\hline
\end{tabular}

The $32 \mu \mathrm{m}$ peak in the small particle spectra, which corresponds to resonance mode "D", is only visible in a logarithmic plot. Figure 6 shows that it is very conspicious for our natural spinel, somewhat weaker for the annealed one, and very weak for an Al-rich crystal like Mg05. We will come back later to this very interesting feature in Sect. 3.2

Considering the lower panel of Fig. 5, we find again that the small particle spectrum of spheres, in its overall shape, has become smoother after annealing. (This was even more evident from the reflectance measurements of Fig. 3.) The double-peak at $17 \mu \mathrm{m}$ has disappeared after the thermal treatment of the crystal. The $13 \mu \mathrm{m}$ emissivity maximum has broadened and shifted towards $13.1 \mu \mathrm{m}$.

In the present context, we restricted the discussion to the case of spherical particles, since we know from the astronomical spectra that the full width at half maximum ( FWHM) of the $13 \mu \mathrm{m}$ feature is only $0.6 \mu \mathrm{m}$ on the average (see Sect. 3). As we have demonstrated in Paper I (Fig. 6), for a continuous distribution of ellipsoids (CDE), the width of the $13 \mu \mathrm{m}$ feature amounts to $2 \mu \mathrm{m}$. Powder transmission spectra also show very broad absorption features - similar to the case of a CDE - and will therefore not be used for the comparison with the spectra of 
circumstellar dust shells. Of course, we cannot exclude that irregularly shaped spinel particles also evolve in oxygen-rich circumstellar shells. But apparently, if such a population of irregularly shaped grains is present at all, it does not dominate the spectral energy distribution.

\section{Comparison of the laboratory data with new ISO spectra}

\subsection{The 8-18 $\mu \mathrm{m}$ wavelength region}

In Paper I, we used 11 ISO-SWS-spectra of semiregular variables to study the dust emission in the trough region between the two silicate bands (i.e., in the wavelength region $12-17 \mu \mathrm{m})$. We focussed on the $13 \mu \mathrm{m}$ band profile - arriving at a mean band position of $13.0 \mu \mathrm{m}$ and an average $F W H M$ of $0.6 \mu \mathrm{m}$ - and found additional minor emission features at 15.8 and $16.8 \mu \mathrm{m}$.

Apart from presenting optical constants of substances that could contribute to $12-17 \mu \mathrm{m}$ dust emission, our present aim is to check the validity of our above mentioned spectroscopic results on the basis of a larger data set. For this purpose, we additionally reduced spectra from 2 open time ISO projects (fkerschb.zzagb2pn; jhron.varlpv) and spectra from the ISO archive by means of the ISO Spectral Analysis Package (ISAP). Figure 7 shows the 8$18 \mu \mathrm{m}$ region of these SWS spectra. The exposure time of the spectra was chosen corresponding to the brightness of the stars. R Dor, for example, was observed with scanning speed 1, whereas for the faintest sample star, CE And, speed 4 was used.

While some of the stars (like CE And, W Hya, $\vartheta$ Aps, RX Boo and R Cas) exhibit more or less classic silicate emission, there is also the peculiar case of $\mathrm{R}$ Cen. The position of its maximum dust emission amounts to about $12 \mu \mathrm{m}$. One possible explanation for this strange spectral shape is that an Al-rich spinel dust (like our Mg07) is responsible both for the 12 and for the $13 \mu \mathrm{m}$ emission (see Fig. 5). In most of the other ISO spectra, no conspicious $12 \mu \mathrm{m}$ emission feature is present. In the residual emission profile of Fig. 8, a small feature is visible at $12 \mu \mathrm{m}$; but since its strength is not comparable with the $13 \mu \mathrm{m}$ emission, it is compatible only with the emissivity of a slightly Al-enriched spinel (see the more detailed discussion below).

It is interesting to note that even for stars with a rather weak $13 \mu \mathrm{m}$ feature like $\mathrm{R}$ Cas, the band position is not shifted towards longer wavelengths as it should be the case if its carrier were core-mantle-particles composed of corundum and an amorphous silicate (see Paper I, Figs. 10 and 11).

For five of our sample stars, Justtanont et al. (1998) have pointed out a correlation between the $13 \mu \mathrm{m}$ band strength and the intensity of the $\mathrm{CO}_{2}$ emission/absorption lines. This correlation is also evident from Fig. 7 .

Table 4 summarizes the basic properties of the sample stars. The LRS classes listed in Col. 6 originate from the LRS atlas (IRAS Science Team 1986); $12 \mu \mathrm{m}$ flux densities were taken from the ISO spectra after reducing the spectral resolution to $R=50$. Data on the gas mass-loss were calculated from the IRAS $60 \mu \mathrm{m}$ fluxes by means of the method outlined by Kerschbaum \& Olofsson (1999).

By the method outlined in Paper I, we derived individual residual emission profiles in the $12-17 \mu \mathrm{m}$ wavelength region. These were then added up (together with the profiles shown in Paper I) to derive a mean residual emission profile, now containing the information from a total of 23 ISO spectra. The result of this procedure is shown in Fig. 8. In spite of the fact that we included twelve new ISO spectra here, the resulting $13 \mu \mathrm{m}$ band profile has remained practically the same as the one shown in Figs. 3 and 14 of Paper I. The mean band position is again $13.0 \mu \mathrm{m}$ and the average $F W H M 0.6 \mu \mathrm{m}$. Note that also the existence of a weak feature at $16.8 \mu \mathrm{m}$ is confirmed by our reinvestigation.

On the basis of the laboratory data presented in Sect. 2, we may now adress the question which $\mathrm{Al} / \mathrm{Mg}$ ratios of spinel are compatible with the observed dust emission. Comparing Fig. 8 with Fig. 5, we recognize that the $12-17 \mu \mathrm{m}$ emission profile is not compatible with large $\mathrm{Al} / \mathrm{Mg}$ ratios. For $\mathrm{Al} / \mathrm{Mg}$-ratios greater than 2.5, the $12 \mu \mathrm{m}$ peak of $C_{\text {abs }}$ becomes comparable in its strength with the $13 \mu \mathrm{m}$ peak, which is definitely not consistent with the astronomical spectra. For $\mathrm{Al} / \mathrm{Mg}$-ratios below 2.19 , the $12 \mu \mathrm{m}$ peak is clearly less conspicious than the one at $13 \mu \mathrm{m}$ and the position of the $13 \mu \mathrm{m}$ band agrees rather well with the peak position observed with ISO. A reasonable overall agreement can be achieved with the small particle spectrum of our stoichiometric synthetic sample Mg10 and with that of the annealed natural spinel. However, the latter, due to its annealing temperature of $1300 \mathrm{~K}$ - which is very close to the temperature for the corundum-spinel transition according to Gail (1998) -, is more likely to represent circumstellar spinel dust. (Recall that the synthetic sample Mg10 was formed at about $2400 \mathrm{~K}$ and therefore has a different degree of disordering than the annealed natural crystal.)

In order to find out whether the $16.8 \mu \mathrm{m}$ is real or spurious, we reduced the spectra of three K-stars: $\alpha$ Tuc, HR 6705 and HD 149447. If the $16.8 \mu \mathrm{m}$ were an artifact caused by the ISO-SWS, it should also show up in the spectra of these stars. This is not the case, though. Only at $16 \mu \mathrm{m}$ do we suspect a spurious feature. It is also visible in Fig. 8 to the left of the lowest-energy $\mathrm{CO}_{2}$-line.

\subsection{Discovery of an emission feature at $32 \mu \mathrm{m}$}

We have seen in Sect. 2.3 that an additional emission band, originating from an $\mathrm{Mg}$-O-vibration, is expected to show up at $32 \mu \mathrm{m}$. In fact, in those of our spectra where the signal-to-noise ratio beyond $30 \mu \mathrm{m}$ is still good, we do see a feature at this wavelength. Figure 9 shows the ISO spectra of R Dor, W Hya, R Hya, T Cep, S Pav and $\vartheta$ Aps in the $10-35 \mu \mathrm{m}$ range together with the emissivity 
D. Fabian et al.: Infrared optical properties of spinels
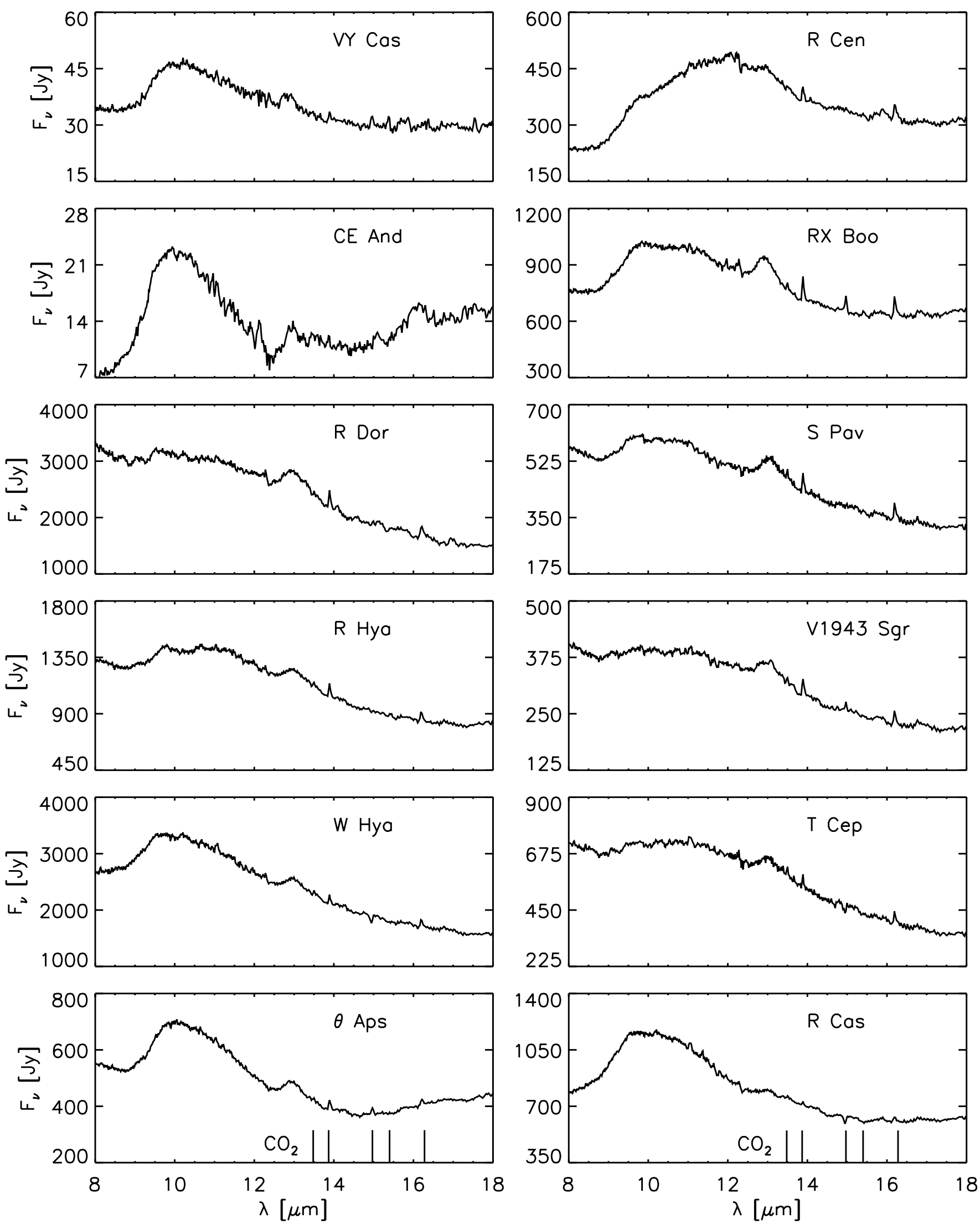

Fig. 7. The reduced ISO-SWS01-spectra in the 8-18 $\mu \mathrm{m}$ wavelength region. The positions of the $\mathrm{CO}_{2}$-lines are only marked in the bottom panels. 
Table 4. Basic properties of the sample stars.

\begin{tabular}{|c|c|c|c|c|c|c|c|c|c|c|}
\hline Name & IRAS Name & Type & $\begin{array}{c}\text { Period } \\
{[\mathrm{d}]}\end{array}$ & Spectrum & LRS & $\begin{array}{l}F_{12} \\
{[\mathrm{Jy}]}\end{array}$ & $\begin{array}{c}v_{\exp } \\
{[\mathrm{km} / \mathrm{s}]}\end{array}$ & $\begin{array}{c}\mathrm{d} M / \mathrm{d} t \\
{\left[M_{\odot} / \mathrm{yr}\right]}\end{array}$ & $\begin{array}{c}13 \mu \mathrm{m} \text { band pos. } \\
{[\mu \mathrm{m}]}\end{array}$ & $\begin{array}{c}F W H M \\
{[\mu \mathrm{m}]}\end{array}$ \\
\hline VY Cas & $00484+6238$ & $\mathrm{SRb}$ & 100 & M6-M7 & 22 & 38 & - & $2 \times 10^{-7}$ & 12.9 & 0.6 \\
\hline CE And & $01265+4624$ & $\mathrm{Lb}$ & - & M2 & 28 & 13 & 12 & $1 \times 10^{-7}$ & 13.0 & 0.6 \\
\hline R Dor & $04361-6210$ & $\mathrm{SRb}$ & 338 & M7 & $1 n$ & 5157 & 6 & $7 \times 10^{-8}$ & 13.1 & 0.75 \\
\hline R Hya & $13269-2301$ & M & 389 & M6e-M9e & 15 & 1293 & 10 & $9 \times 10^{-8}$ & 13.1 & 0.7 \\
\hline W Hya & $13462-2807$ & SRa & 361 & M8e-M9e & 02 & 2665 & 8 & $7 \times 10^{-8}$ & 13.0 & 0.5 \\
\hline$\vartheta \mathrm{Aps}$ & $14003-7633$ & $\mathrm{SRb}$ & 119 & M3 & 22 & 734 & 6 & $1 \times 10^{-7}$ & 13.0 & 0.6 \\
\hline R Cen & $14129-5940$ & $\mathrm{M}$ & 546 & $\mathrm{M} 4 \mathrm{e}-\mathrm{M} 8 \mathrm{e}$ & 22 & 485 & - & $7 \times 10^{-8}$ & 13.0 & 0.5 \\
\hline RX Boo & $14219+2555$ & $\mathrm{SRb}$ & 340 & M7e-M9e & $2 n$ & 895 & 10 & $1 \times 10^{-7}$ & 13.0 & 0.6 \\
\hline S Pav & $19510-5919$ & SRa & 381 & M7 & 14 & 502 & 9 & $9 \times 10^{-8}$ & 13.1 & 0.7 \\
\hline V1943 Sgr & $20038-2722$ & $\mathrm{Lb}$ & - & M8 & 15 & 359 & 7 & $1 \times 10^{-7}$ & 13.0 & 0.7 \\
\hline T Cep & $21088+6817$ & M & 388 & M6e & 15 & 753 & 6 & $8 \times 10^{-8}$ & 13.1 & 0.7 \\
\hline R Cas & $23558+5106$ & M & 430 & M6e-M10e & 24 & 868 & 12 & $2 \times 10^{-7}$ & 13.1 & 0.5 \\
\hline
\end{tabular}

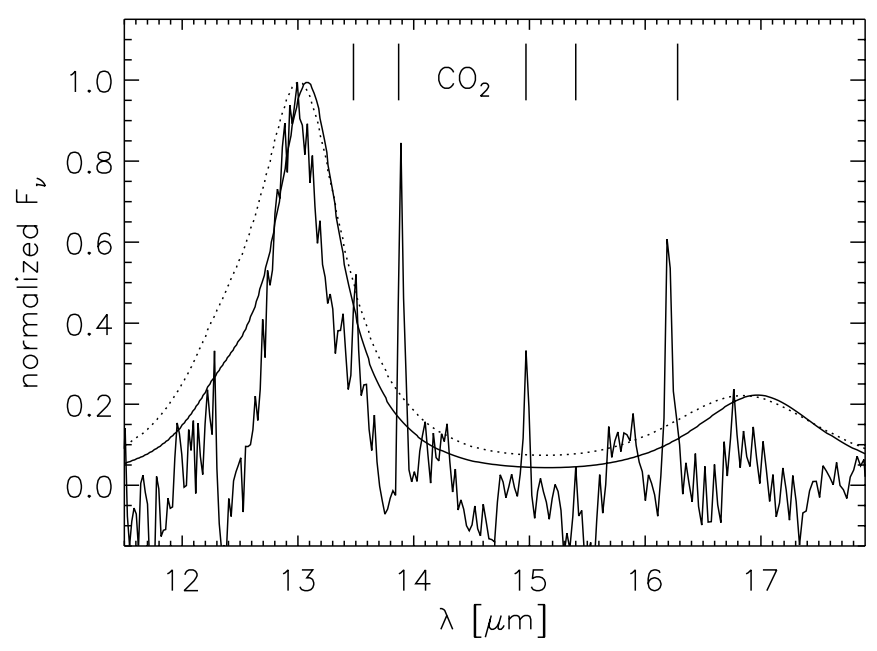

Fig. 8. The average residual emission profile in the $12-18 \mu \mathrm{m}$ range, derived by summing up the normalised individual residuals both of the spectra presented in Paper I and of those shown in the previous figure. For comparison, the normalized emissivities of our sample Mg10 (dotted) and of the annealed natural crystal (solid) are shown.

of annealed natural and stoichiometric synthetic spinel. All these stars show a rather narrow $32 \mu \mathrm{m}$ emission band which seems to be well correlated in its strength with the 13 and $16.8 \mu \mathrm{m}$ local emission intensities. A systematic investigation of this feature is definitely desirable.

As a first step, we have derived a mean profile of the $32 \mu \mathrm{m}$ feature exactly in the same way as for the residual emission in the $12-18 \mu \mathrm{m}$ range, but of course only on the basis of the beforementioned six high signal-tonoise ISO spectra. The result is shown in Fig. 10, together with the continuum-subtracted emissivities of our samples Mg10 and Mg10-ann. Again, the annealed natural spinel turns out to be quite similar to the feature carrier with respect to the band position. With respect to the feature width, the agreement between the ISO data
$\left(F W H M_{32 \mu \mathrm{m}} \approx 0.5 \mu \mathrm{m}\right)$ and the emissivity of annealed spinel $\left(F W H M_{32} \mu \mathrm{m} \approx 1.5 \mu \mathrm{m}\right)$ is not so good. However, it should be taken into account that the mean band profile shown in Fig. 10 remains to be re-examined on the basis of a larger number of observations.

Crystalline silicates can be excluded as carrier of this feature on the basis of laboratory studies performed by Jäger et al. (1998). In accordance with the result of Jäger et al., Molster et al. (1999) found silicate features in their spectra of AFGL 4106 at 32.8 and $33.6 \mu \mathrm{m}$, but none between 31.5 and $32 \mu \mathrm{m}$.

The peaks at 20 and $28 \mu \mathrm{m}$ which are also present in the six plotted spectra (the latter also in the residual profile of Fig. 10), are instrumental artifacts, the former being probably due to a wrong gradient at the "blue" end of SWS band 3D $(19.4-27.5 \mu \mathrm{m})$, the latter being due to a red leak in SWS band 3E $(27.4-29.1 \mu \mathrm{m})$.

\subsection{Is there a correlation between 10 and $13 \mu \mathrm{m}$ band strengths?}

A puzzling question, which can also provide constraints on the origin of the $13 \mu \mathrm{m}$ feature, is whether there exists a correlation between its strength and the intensity of the silicate dust emission. Considering Fig. 8 of Begemann et al. (1997), one will be tempted to answer this question with a definite "yes". However, we found it necessary to reexamine this point using the following method. First, we rebinned the ISO spectra to a spectral resolution of $R=50$. From these rebinned spectra, we took the flux values $F 10, F 12, F 13$ and $F 14$ at $10,12,13$ and $14.3 \mu \mathrm{m}$ to derive an effective $13 \mu \mathrm{m}$ feature strength:

$F 13 e=F 13-\frac{F 12+F 14}{2}$.

This quantity - which we calculated also for the sample stars from Paper I - was then divided by the flux density at $7 \mu \mathrm{m}, F 7$, to correct for the stellar distances 

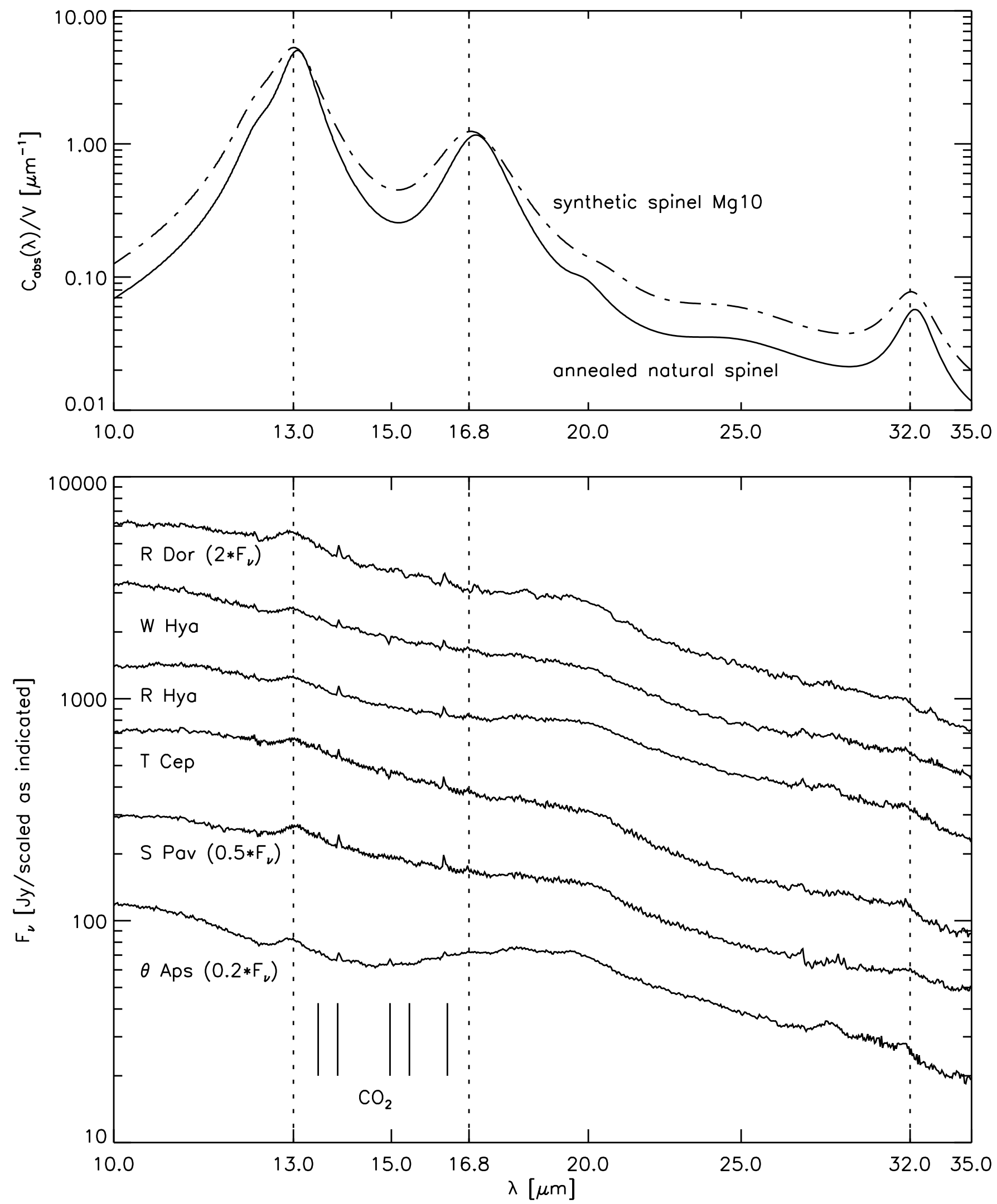

Fig. 9. Comparison of the ISO-spectra of six bright stars from our sample with the emissivity of annealed natural and Mg-rich synthetic spinel in the $7-40 \mu \mathrm{m}$ wavelength range. Note the presence of the 13,17 and $32 \mu \mathrm{m}$ features in all of the three ISO spectra. The above mentioned spectral features are highlighted by dashed vertical lines. 


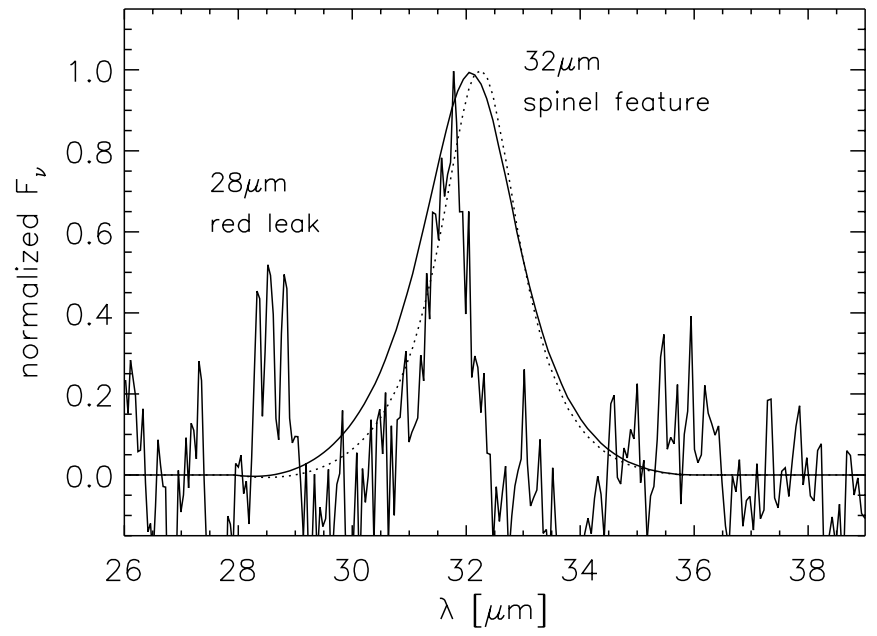

Fig. 10. The average residual emission profile in the $26-39 \mu \mathrm{m}$ range, derived in the same way as the profile shown in Fig. 8, but on the basis of the six brightest sample spectra only. Again, the normalized emissivities of our sample Mg10 (dotted) and of the annealed natural crystal (solid) is shown for comparison.

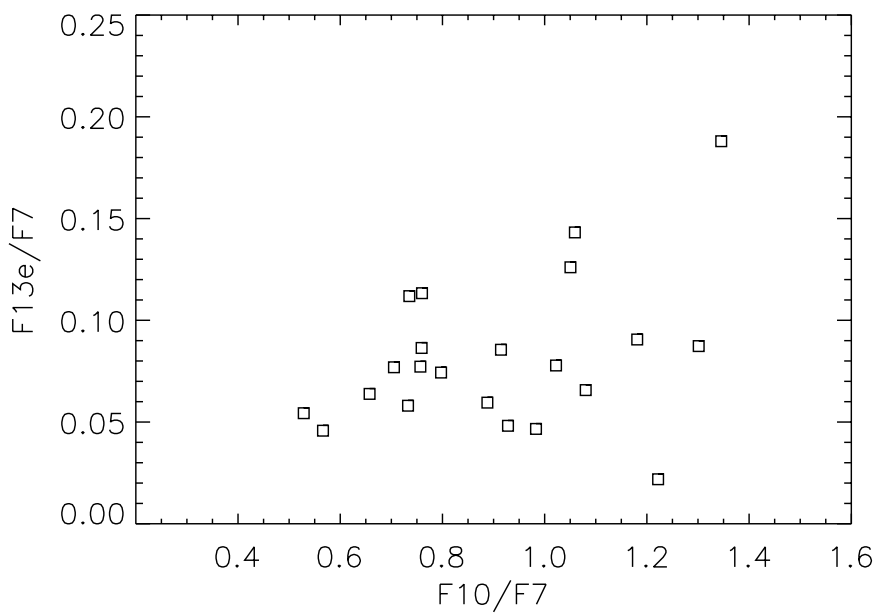

Fig. 11. The effective $13 \mu \mathrm{m}$ feature strength as a function of the $10 \mu \mathrm{m}$ flux density (corrected for the stellar distances). We find no one-to-one correlation between both quantities.

(under the assumption of comparable intrinsic luminosities of our sample stars). Finally, we plotted $F 13 \mathrm{e} / F 7$ versus $F 10 / F 7$. The result is shown in Fig. 11. It seems clear that

a) there is no one-to-one correlation between the effective 13 and $10 \mu \mathrm{m}$ band strengths, but

b) there is an "upper envelope" for $F 13 \mathrm{e} / F 7$ vs. $F 10 / F 7$, indicating that for a given (distance-corrected) $10 \mu \mathrm{m}$ emission, F13e cannot become arbitrarily large, but a given $13 \mu \mathrm{m}$ band strength does not presuppose a certain intensity of the $10 \mu \mathrm{m}$ dust emission.

Altogether, it is rather unlikely that the 13 and the $10 \mu \mathrm{m}$ emission are due to one and the same carrier substance.

\section{Conclusions}

We have studied the infrared optical properties of $\mathrm{Mg}-\mathrm{Al}-$ oxides with spinel structure, highlighting both the effect of annealing natural spinel and the influence of nonstoichiometry on the complex index of refraction.

It was shown that beyond about $1200 \mathrm{~K}$, a structural disordering of the cation distribution of natural spinel takes place, leading to a significant change in the optical constants. The position of the $13 \mu \mathrm{m}$ band expected to arise from small spherical spinel particles is shifted to the "blue" by $0.3 \mu \mathrm{m}$ in the course of annealing. The $17 \mu \mathrm{m}$ band loses its double-peak structure.

Synthetic aluminium spinels, if stoichiometric, have the same lattice structure and IR-optical properties as annealed natural ones do. However, for nonstoichiometric, Al-rich samples, a $12 \mu \mathrm{m}$ resonance band shows up in the small particle spectra in addition to the $13 \mu \mathrm{m}$ band feature. In other words, Al-rich spinels show spectra intermediate between those of stoichiometric spinel and those of $\gamma-\mathrm{Al}_{2} \mathrm{O}_{3}$. This result is consistent with those of other authors (Hafner \& Laves 1961; Chihara et al. 2000).

By deriving mean residual emission profiles in the 12 $18 \mu \mathrm{m}$ and $26-39 \mu \mathrm{m}$ wavelength regions from ISO spectra of oxygen-rich AGB stars, we have shown that nearstoichiometric spinel is indeed an excellent candidate for the carrier of the emission features at $13,16.8 \mu \mathrm{m}$, and a newly dicovered one at $32 \mu \mathrm{m}$. Nonstoichiometry with $\mathrm{Al} / \mathrm{Mg}$ ratios larger than 2.5 is not compatible with the observed dust features.

The derivation of optical constants of refractory oxides is only a first step in studying the role of these substances in the context of circumstellar dust formation. A rather straightforward application of our results is to calculate equilibrium dust temperatures as functions of the distance from the stellar photosphere (see Woitke 1999, Fig. 2). A second, more sophisticated way to obtain additional information on the formation of oxides around M-giants will be condensation experiments. We have to leave these tasks up to future investigations.

Acknowledgements. We thank Gabriele Born, Jena, for preparing our samples. Anton Beran, Institut für Mineralogie und Kristallografie, Universität Wien, kindly provided us with various synthetic and natural minerals. Josef Hron gave us hints for the reduction of the spectra from his open time project. Thomas Henning's and an anonymous referee's suggestions helped to improve our original manuscript.

This work was supported by the Deutsche Forschungsgemeinschaft, DFG project number Do 575/4-1 and by the Austrian Fonds zur Förderung der wissenschaftlichen Forschung under project number S7308-AST. TP received travels grant from the project FIRST-PACS/Phase I, financed by the Austrian federal ministry of transport, innovation and technology (bm:vit). FK's work was supported by APART (Austrian Programme for Advanced Research and Technology) from the Austrian Academy of Sciences.

The ISO Spectral Analysis Package (ISAP) is a joint development by the LWS and SWS Instrument Teams and Data 
Centers. Contributing institutes are CESR, IAS, IPAC, MPE, RAL and SRON.

\section{References}

Andreozzi, G. B., Princivalle, F., Skobgy, H., \& Della Giusta, A. 2000, Amer. Min., 85, 1164

Begemann, B., Dorschner, J., Henning, Th., et al. 1997, ApJ, 476, 199

Bohren, C. F., \& Huffman, D. R. 1983, Absorption and Scattering of Light by Small Particles (John Wiley, New York)

Chihara, H., Tsuchiyama, A., Koike, C., et al. 2000, in Disks, Planetesimals and Planets, ed. F. Garzon, C. Eiroa, C. D. de Winter, et al., ASP Conf. Ser., in press

Choi, B.-G., Huss, G. R., Wasserburg, G. J., et al. 1998, Science, 282, 1284

Choi, B.-G., Wasserburg, G. J., \& Huss, G. R. 1999, ApJ, 522, L 133

Gail, H.-P. 1998, A\&A, 332, 1099

Gail, H.-P., \& Sedlmayr, E. 1998, in Chemistry and Physics of Molecules and Grains in Space, Faraday Discussion No. 109, The Faraday Division of the Royal Society of Chemistry, London, 303

Glaccum, W. 1995, in Airborne Astronomy Symposium on the Galactic Ecosystem, ed. M. R. Haas, J. A. Davidson, \& E. F. Erickson, ASP Conf. Ser., 73, 395

Hafner, S., \& Laves, F. 1961, Z. Krist., 115, 321

Henning, Th., Il'in, V. B., Krivova, N. A., et al. 1999, A\&AS, 136,405

Hron, J., Aringer, B., \& Kerschbaum, F. 1997, A\&A, 322, 280

IRAS Science Team 1986, A\&AS, 65, 607 (LRS Atlas)

Jäger, C., Molster, F. J., Dorschner, J., et al. 1998, A\&A, 339, 904

Justtanont, K., Feuchtgruber, H., de Jong, T., et al. 1998, A\&A, 330, L17-L20

Kerschbaum, F., \& Olofsson, H. 1999, A\&AS, 138, 299

Kerschbaum, F., Posch, Th., \& Aringer, B. 2000, in Proceedings of the Conference, ISO beyond the Peaks, Villafranca del Castillo, Spain (ESA SP-456)
Kerschbaum, F., \& Olofsson, H. 2001, in preparation

Koike, C., Kaito, C., Yamamoto, T., et al. 1995, Icarus, 114, 203

Kozasa, T., \& Sogawa, H. 1997, Ap\&SS, 251, 165

Kozasa, T., \& Sogawa, H. 1998, Ap\&SS, 255, 437

Molster, F., Waters, L. B. F. M., Trams, N., et al. 1999, A\&A, 350, 163

Nittler, L. R. 1997, in Astrophysical Implications of the Laboratory Study of Presolar Materials, ed. T. J. Bernatowicz, \& E. Zinner, AIP Conf. Proc., 402, 59

O'Horo, M. P., Frisillo, A. L., \& White, W. B. 1973, J. Phys. Chem. Solids, 34, 23

Onaka, T., de Jong, T., \& Willems, F. J. 1989, A\&A, 218, 169

Palik, E. D. (ed.) 1985-1998, Handbook of Optical Constants of Solids, 3 vols. (Academic Press, Boston)

Posch, Th., Kerschbaum, F., Mutschke, H., et al. 1999, A\&A, 352, 609 (Paper I)

Preudhomme, J., \& Tarte, P. 1971, Spectrochim. Acta, 27A, 1817

Sedlmayr, E., \& Krüger, D. 1997, in Astrophysical Implications of the Laboratory Study of Presolar Materials, ed. T. Bernatowicz, \& E. Zinner, AIP Conf. Proc., 402, 425

Sloan, G. C., LeVan, P. D., \& Little-Marenin, I. R. 1996, ApJ, 463,310

Speck, A. K., Barlow, M. J., Sylvester, R. J., \& Hofmeister, A. M. 2000, A\&AS, 146, 437

Strübel, G. 1995, Mineralogie, Ferdinand Enke Verlag Stuttgart

Tropf, W. J., \& Thomas, M. E. 1991, in Handbook of Optical Constants of Solids II, ed. E. D. Palik (Academic Press, Boston), 883

Vardya, M. S., De Jong, T., \& Willems, F. J. 1986, ApJ, 304, L29

Viertel, H. U., \& Seifert, F. 1979, N. Jb. Miner. Abh., 134, 167

White, W. B., \& De Angelis, B. A. 1967, Spectrochim. Acta, 23A, 985

Woitke, P. 1999, in Astronomy with Radioactivities, MPE Report 274, ed. R. Diehl, \& D. Hartmann, 163 